\title{
Sacral Neuromodulation Treatment for Non-neurogenic Urological Disorders: Experience of a Single Center in Turkey
}

\author{
(D) Adem Emrah Coğuplugil, (D) Sercan Yılmaz, (D) Bahadır Topuz, (D) Murat Zor, (D) Engin Kaya, (D) Mesut Gürdal \\ University of Health Sciences Turkiye, Gülhane Training and Research Hospital, Clinic of Urology, Ankara, Turkiye
}

\section{What's known on the subject? and What does the study add?}

Sacral neuromodulation (SNM) has been proven by many studies to be an effective and safe minimal invasive therapy for the treatment of overactive bladder, bladder pain syndrome/interstitial cystitis, and idiopathic non-obstructive urinary retention. Efficacy and safety results of this study is similar with the literature. On the other hand, this study is presenting the experience of a center in Turkey with regard to SNM treatment in non-neurogenic urological disorders.

\begin{abstract}
Objective: We evaluated the success rate and complications of sacral neuromodulation (SNM) in patients with non-neurogenic urological disorders. Materials and Methods: We retrospectively evaluated patients with an overactive bladder (OAB), bladder pain syndrome/interstitial cystitis (BPS/ IC), and idiopathic non-obstructive urinary retention (IUR), who underwent SNM between 2015 and 2020. SNM was recommended for patients with $\mathrm{OAB}$ and BPS/IC who previously had unsuccessful conservative and medical therapies and botulinum toxin injections. Success was defined as more than $50 \%$ improvement in clinical symptoms or voiding diary parameters in patients with $0 A B$; more than $50 \%$ improvement in storage symptoms or subjective pain improvement or improvement after pain medications in patients with BPS/IC; more than 50\% reduction in urethral catheterization rate in patients with IUR. We reviewed the success rates and complications.

Results: Twenty-four patients underwent the first stage of SNM and 16 patients $(66.6 \%)$ received permanent implantation. Ten patients were female (62.5\%) and six were male (37.5\%). The mean age was 36.9 years. Seven patients (43.7\%) had OAB, three patients (18.7\%) had BPS/IC, and six patients (37.5\%) had IUR. After a mean follow-up of 42.3 months, the overall success rate was $87.5 \%$ for all indications. The success rate was 100\%, 100\%, and 66.7\% for OAB, BPS/IC, and IUR, respectively. Four patients underwent surgical reintervention: two had their devices removed due to failure (50\%), one had their implantable pulse generator (IPG) repositioned due to serious pain (25\%), and one changed IPG due to malfunction (25\%).
\end{abstract}

Conclusion: SNM is a safe and effective minimally invasive therapy for patients with non-neurogenic urological disorders.

Keywords: Bladder pain syndrome, idiopathic urinary retention, interstitial cystitis, overactive bladder, sacral neuromodulation

\section{Introduction}

Sacral neuromodulation (SNM) has proven to be an effective treatment option for refractory overactive bladder $(\mathrm{OAB})$ and idiopathic nonobstructive urinary retention (IUR) (1). The Food and Drug Administration has approved SNM for treating $O A B$ and IUR (2). Additionally, SNM has been widely used for treating bladder pain syndrome/interstitial cystitis (BPS/IC) and neurogenic bladder (3). Several SNM studies are present in the current literature, reporting long-term success and safety $(1,4)$.
Currently, there are no articles on the success and complications of SNM in urological disorders in the English literature published from Turkey. This is the first study from Turkey, where we present our experience with SNM for treating OAB, IUR, and BPS/IC.

\section{Materials and Methods}

Our institutional ethical board approved this study (University of Health Sciences Turkey, Gülhane Training and Research Hospital, approval number: 19/80, date: 28.05.2019). Following

Correspondence: Adem Emrah Coğuplugil MD, University of Health Sciences Turkiye, Gülhane Training and Research Hospital, Clinic of Urology, Ankara, Turkiye Phone: +90 5303809524 E-mail: aemrahco@yahoo.com ORCID-ID: orcid.org/0000-0002-6240-4989

Received: 05.02.2021 Accepted: 04.05.2021

Cite this article as: Coğuplugil AE, Yılmaz S, Topuz B, Zor M, Kaya E, Gürdal M. Sacral Neuromodulation Treatment for Non-neurogenic Urological Disorders: Experience of a Single Center in Turkey. J Urol Surg 2021;8(4):261-265.

๑Copyright 2021 by the Association of Urological Surgery / Journal of Urological Surgery published by Galenos Publishing House. 
the ethical approval, we retrospectively reviewed the medical records of all patients who underwent implantable pulse generator (IPG) placement (Interstim ${ }^{\text {TM }}$, Medtronic, Minneapolis, USA) in our center between January 2015 and May 2020. Patients' demographics, indications for SNM, treatment success, follow-up period, and complications (including revisions) were recorded.

We assessed all patients using a thorough medical history, physical examination, cystoscopy, urodynamic testing, neurological and psychiatric examination, and seven-day voiding diary (frequency, urgency, incontinence episodes, voided volume, and self-catheterization episodes and volume). Inclusion criteria were as follows: patients in the age range of 18 to 55 years, urinary urgency, frequency, urgency incontinence, pain related to the urinary bladder, dysuria, and urinary retention. Exclusion criteria were as follows: patients older than 55 years bladder outlet obstruction, urethral stricture, urinary tract cancer, urinary tract infection, pregnancy, and neurological or psychiatric pathology. SNM treatment indications included refractory $O A B$, refractory $B P S / I C$, and IUR.

$O A B$ was diagnosed according to the definition of the International Continence Society (5). BPS/IC was diagnosed according to the definition of the European Society for the Study of Interstitial Cystitis (ESSIC) (6). IUR was defined as "neurologically healthy patients who are unable to urinate or had difficulty urinating with a significant residual urine volume, greater than $300 \mathrm{~mL}$, without urethral stricture or bladder outlet obstruction." Patients defined as "refractory $O A B$ " were those who experienced no improvement using one antimuscarinic drug or more for three months or those who were unable to tolerate the side effects of antimuscarinics (7). All patients with $O A B$ and $B P S / I C$ had botulinum toxin injections before SNM treatment. In patients with $O A B$, failure of intradetrusor botulinum toxin injections was defined as less than $50 \%$ improvement or worsening of symptoms following the injections. Refractory BPS/IC was defined as less than $50 \%$ improvement or worsening of symptoms following oral and intravesical treatments, hydrodistension, fulguration, or intradetrusor botulinum toxin injections.

All patients underwent two-stage SNM implantation. The first stage was performed in the operating room under local anesthesia and sedation. A 22-G spinal needle was placed percutaneously into each S3 foramen under fluoroscopic guidance, and stimulation was then performed. Proper needle location was assessed using sensorial (vaginal or perineal sensation) and motor (bellow-like contraction of the anal sphincter or plantar flexion of the great toe) responses during stimulation. The needle with the best stimulation responses was retained and the other one removed. Then, a small incision was made and the tined permanent lead was placed through the needle tract. Proper tined lead placement was confirmed using fluoroscopy and repeat stimulation. The tined lead was then connected to an extension wire, which was tunneled subcutaneously to the contralateral upper lateral side of the hip and connected to an external temporary generator. Patients were taught how to work the external generator. During the test stimulation period (7-30 days), patients were seen daily for the first five days to assess the sensorial response and symptom improvement. Patients completed a seven-day voiding diary (frequency, urgency, incontinence episodes, voided volume, and self-catheterization episodes and volume). After seven days, the patients were contacted by phone. If a patient reported a decreased vaginal or perineal sensation, reprogramming was done. Reprogramming was also done for patients who experienced no clinical improvement after the first week and repeated if necessary. Success was defined as more than 50\% improvement in clinical symptoms or voiding diary parameters in patients with $\mathrm{OAB}$; more than $50 \%$ improvement in storage symptoms or subjective pain improvement or improvement after pain medications in patients with BPS/IC; less than 50\% reduction in urethral catheterization rate in patients with IUR. If successful results were achieved during the test stimulation period, then the patients underwent permanent IPG placement under local anesthesia. Improvement of less than $50 \%$ or worsening of the symptoms was defined as failure for all indications.

All patients were followed up at three, six, and twelve months postoperatively and yearly thereafter, or if clinically indicated. Overall symptom improvement was reported using a voiding diary and direct interview on each visit. Symptom scores were not used. Also, PVR measurement was performed for patients with IUR. During the follow-up, SNM was considered successful if there was an initial improvement of more than 50\% in clinical symptoms or voiding diary parameters persisted compared with baseline. Due to the small number of patients and retrospective design, descriptive statistical data (percentage, mean, and range) were used.

\section{Results}

Twenty-four patients underwent the first stage of SNM from January 2015 to May 2020 in our urology department. Eight patients (33.3\%) failed the test period, and 16 patients (66.6\%) received permanent IPG implantation. During implantation, motor responses were achieved in 15/16 patients (93.7\%) and sensory responses were achieved in 12/16 patients (75\%). Our implantation rate was $66.6 \%$. Of these 16 patients, 10 were female $(62.5 \%)$ and six were male $(37.5 \%)$. The mean age was 36.9 (range: $20-55)$ years. Seven patients $(43.7 \%)$ had $O A B_{1}$ three patients (18.7\%) had BPS/IC, and six patients (37.5\%) had 
IUR. After a mean follow-up of 42.3 months (range: 5-80), our overall success rate was $87.5 \%$ for all indications. The success rate was 100\%, 100\%, and 66.7\% for OAB, BPS/IC, and IUR, respectively (Table 1$)$.

No local wound complication (hematoma, infection, etc.) occurred in the early postoperative period. Also, no serious complications occurred. Four patients (25\%) experienced complications during the follow-up period: Two patients experienced device failure, one patient had IPG site pain, and one patient experienced IPG malfunction. Four patients underwent surgical reintervention: Two had their devices removed due to failure (50\%), one had their IPG repositioned due to serious pain (25\%), and one changed IPG due to malfunction (25\%) (Table 1). Failure occurred in two patients with IUR at three and 47 months after implantation. Follow-up with clean intermittent catheterization was recommended for these patients.

\begin{tabular}{|c|c|c|c|c|}
\hline & All & OAB & BPS/IC & IUR \\
\hline $\begin{array}{l}\text { Number of } \\
\text { patients, n (\%) }\end{array}$ & 16 & $7(43.7)$ & 3 (18.7) & $6(37.5)$ \\
\hline $\begin{array}{l}\text { Mean age (range), } \\
\text { years }\end{array}$ & $36.9(20-55)$ & 31.1 & 49 & 37 \\
\hline $\begin{array}{l}\text { Gender: female/ } \\
\text { male, } n\end{array}$ & $10: 6$ & $3: 4$ & $3: 0$ & $4: 2$ \\
\hline $\begin{array}{l}\text { Mean follow-up, } \\
\text { months }\end{array}$ & 42.3 & 37.8 & 37.6 & 42.5 \\
\hline Success, \% & 87.5 & 100 & 100 & 66.7 \\
\hline $\begin{array}{l}\text { Complications, n } \\
\text { - Failure } \\
\text { - IPG site pain } \\
\text { - IPG malfunction }\end{array}$ & $\begin{array}{l}4 \\
2 \\
1 \\
1\end{array}$ & $\begin{array}{l}0 \\
0 \\
0 \\
0\end{array}$ & $\begin{array}{l}0 \\
0 \\
0 \\
0\end{array}$ & $\begin{array}{l}4 \\
2 \\
1 \\
1\end{array}$ \\
\hline
\end{tabular}

\section{Discussion}

SNM is a safe and long-term effective therapy for patients with nonneurogenic lower urinary tract dysfunction (LUTD) (2). The precise mode of action of SNM still remains largely unknown (4). It is thought that SNM works by modulating reflexes at the cord level; however, supraspinal pathways also have a role (8).

Our overall success rate was $87.5 \%$ at a mean follow-up 42.3 months, and the success rates for $O A B, B P S / I C$, and IUR were $100 \%, 100 \%$, and $66.7 \%$, respectively. These results are similar to those of other SNM studies. In a retrospective study by Sutherland et al. (4), a 69\% success rate was reported after SNM implantation in patients with voiding dysfunction with a mean follow-up of 22 months. Peeters et al. (8) reported a 70\% success rate in patients with urgency incontinence and a 73\% success rate in patients with IUR at a mean follow-up of 47 months. In another retrospective study with a median follow-up of 9.7 years, Ismail et al. (9) reported a $63 \%$ success rate in patients with OAB. Siegel et al. (10) reported an 83\% success rate of SNM in patients with $O A B(10)$. Zhang et al. (3) reported that the success rates in patients with $O A B, B P S / I C$, and IUR were $42.5 \%, 72.4 \%$, and $51.6 \%$, respectively. Gajewski and Al-Zahrani (11) reported that the rate of permanent IPG implantation was $59 \%$, and the success rate in patients with BPS/IC was $72 \%$, at a mean-follow-up of 61.5 months.

The most common adverse event reported in the literature was pain at the implant site (15\%-42\%) (2). No serious complications were reported $(2,4)$. van Kerrebroeck et al. (1) reported that 20\% of the patients experienced adverse events resulting in surgical intervention at the one-year follow-up. This rate increased to $42.1 \%$ at five-year follow-up. The most common surgical complications requiring surgical intervention were IPG site pain, suspected lead migration, and new pain or undesirable change in stimulation. Other complications reported in the literature were loss of efficacy, device problem, adverse change in bowel function, infection, and suspected neuropraxia (12). The surgical revision rate was between $13-47 \%(9,13)$. The most common reason for surgical revision was pain at the site of implantation $(2,13)$. The reintervention rate is high in long-term follow-up and tends to be within the first two years after the implantation (2). Our complication rate was $25 \%$. Four patients underwent surgical intervention: Two had their devices removed due to failure $(50 \%)$, one had their IPG repositioned due to serious pain (25\%), and one changed IPG due to malfunction (25\%). All complications occurred in patients with IUR. Additionally, none of our patients experienced serious complications.

The number of our patients is small because we cannot provide SNM to every patient with refractory OAB and BPS/ IC. SNM and botulinum toxin injections are both effective and recommended for treating patients with $\mathrm{OAB}$ and BPS/IC who failed conservative and initial therapies. No hierarchy has been implied between botulinum toxin and SNM $(14,15)$. In our country, the social security institution allows implantation of SNM in neurologically and psychologically healthy patients with $O A B$ and $B P S / I C$, who failed conservative and initial medical therapies and intradetrusor botulinum toxin injection. Therefore, it is mandatory to use intradetrusor botulinum toxin injections in patients with $\mathrm{OAB}$ and BPS/IC before SNM implantation. In fact, this clinical practice is performed to reduce the treatment costs of patients with OAB and BPS/IC since SNM is an expensive treatment option. In randomized studies conducted on patients with $O A B$, it has been shown that SNM treatment is more expensive than botulinum toxin injections $(16,17)$.

In our study, a previous history of psychiatric disease was an exclusion criterion since, in some studies, psychiatric disorders 
were associated with poor results and adverse events. In a study by Weil et al. (18) that reported SNM treatment results in 36 patients with chronic voiding dysfunction, all patients with a previous history of psychological disorder or sexual abuse had a good response to temporary stimulation. However, the median duration of the therapeutic effect was only 12 months in patients with a previous psychiatric history, and $82 \%$ of these patients showed poor results compared with $28 \%$ of the patients without a history of psychiatric disorders (18). White et al. (19) reported a high rate of implant removal in patients with a psychiatric disease history but could not show a significant relationship between psychiatric history and adverse events (19). Marcelissen et al. (20) reported that a history of psychiatric disease was unrelated to the outcome of the test stimulation. However, patients with a history of psychiatric disease more likely encounter adverse events with permanent SNM treatment.

Age was associated with the success rate of SNM. Peters et al. (21) reported that advanced age was negatively associated with SNM success. Amundsen et al. (22) reported in a prospective study that, in patients with refractory urge incontinence who were treated with SNM, age older than 55 years and more than three chronic conditions were independent factors associated with a lower cure rate. Sherman et al. (23) reported that an age less than 55 years was positively associated with SNM treatment. Therefore, we included patients younger than 55 years old in our study.

When placing the quadripolar electrode, it is important to obtain sensory and motor responses. Cohen et al. (24) investigated whether intraoperative motor or sensory response is more predictive of a successful SNM treatment. The authors concluded that a positive test stimulation is more likely when intraoperative lead placement causes a positive motor response compared with sensory response (24). Peters et al. (21) evaluated the impact of assessing sensory responses during quadripolar lead placement in patients with refractory voiding symptoms. They found that, during permanent lead placement, routinely assessing the sensory response insignificantly impacts the success rate of IPG implant and the clinical outcomes of SNM (22). We tried obtaining motor and sensory responses in each patient, and we achieved motor responses in $93.7 \%$ of patients and sensory responses in $75 \%$ of patients.

\section{Study Limitations}

The main limitations of this study were its retrospective design and a small number of patients. However, this is the first study from Turkey reporting on SNM treatment outcomes in urological disorders.

\section{Conclusion}

SNM is a safe and effective minimally invasive therapy in patients with $\mathrm{OAB}, \mathrm{BPS} / \mathrm{IC}$, and IUR and should be considered before any invasive surgical intervention is planned. Several studies are published in English literature, but this is the first study from Turkey reporting on SNM treatment outcomes in urological disorders.

\section{Ethics}

Ethics Committee Approval: Our institutional ethical board approved this study (University of Health Sciences Turkey, Gülhane Training and Research Hospital, approval number: 19/80, date: 28.05.2019).

Informed Consent: Retrospective study.

Peer-review: Externally peer-reviewed.

\section{Authorship Contributions}

Surgical and Medical Practices: A.E.C., S.Y., M.G., Concept: A.E.C., M.G., Design: A.E.C., M.G., Data Collection or Processing: A.E.C., Analysis or Interpretation: A.E.C., Literature Search: A.E.C., S.Y., B.T., M.Z., E.K., Writing: A.E.C., M.G.

Conflict of Interest: No conflict of interest was declared by the authors.

Financial Disclosure: The authors declare that they have no relevant financial.

\section{References}

1. van Kerrebroeck PE, van Voskuilen AC, Heesakkers JP, Lycklama á Nijholt AA Siegel S, Jonas U, Fowler CJ, Fall M, Gajewski JB, Hassouna MM, Cappellano F, Elhilali MM, Milam DF, Das AK, Dijkema HE, van den Hombergh U. Results of sacral neuromodulation therapy for urinary voiding dysfunction: outcomes of a prospective, worldwide clinical study. J Urol 2007;178:20292034.

2. Tutolo M, Ammirati E, Heesakkers J, Kessler TM, Peters KM, Rashid T, Sievert KD, Spinelli M, Novara G, Van der Aa F, De Ridder D. Efficacy and Safety of Sacral and Percutaneous Tibial Neuromodulation in Non-neurogenic Lower Urinary Tract Dysfunction and Chronic Pelvic Pain: A Systematic Review of the Literature. Eur Urol 2018;73:406-418.

3. Zhang P, Wang JY, Zhang Y, Liao L, Lv JW, Ling Q, Wei ZQ, Zhong T, Xu ZH Wen W, Li JY, Luo DY. Results of Sacral Neuromodulation Therapy for Urinary Voiding Dysfunction: Five-Year Experience of a Retrospective, Multicenter Study in China. Neuromodulation 2019;22:730-737.

4. Sutherland SE, Lavers A, Carlson A, Holtz C, Kesha J, Siegel SW. Sacral nerve stimulation for voiding dysfunction: One institution's 11-year experience. Neurourol Urodyn 2007;26:19-36.

5. Abrams P, Cardozo L, Fall M, Griffiths D, Rosier P, Ulmsten U, van Kerrebroeck $\mathrm{P}$, Victor A, Wein A; Standardisation Sub-committee of the International Continence Society. The standardisation of terminology of lower urinary tract function: report from the Standardisation Sub-committee of the International Continence Society. Neurourol Urodyn 2002;21:167-178.

6. van de Merwe JP, Nordling J, Bouchelouche P, Bouchelouche K, Cervigni M, Daha LK, Elneil S, Fall M, Hohlbrugger G, Irwin P, Mortensen S, van Ophoven 
A, Osborne JL, Peeker R, Richter B, Riedl C, Sairanen J, Tinzl M, Wyndaele JJ. Diagnostic criteria, classification, and nomenclature for painful bladder syndrome/interstitial cystitis: an ESSIC proposal. Eur Urol 2008;53:60-67.

7. Phé $V$, de Wachter $S$, Rouprêt $M$, Chartier-Kastler E. How to define a refractory idiopathic overactive bladder? Neurourol Urodyn 2015;34:2-11.

8. Peeters K, Sahai A, De Ridder D, Van Der Aa F. Long-term follow-up of sacral neuromodulation for lower urinary tract dysfunction. BJU Int 2014;113:789-794.

9. Ismail $S$, Chartier-Kastler E, Perrouin-Verbe MA, Rose-Dite-Modestine J, Denys P, Phé V. Long-Term Functional Outcomes of S3 Sacral Neuromodulation for the Treatment of Idiopathic Overactive Bladder. Neuromodulation 2017;20:825-829.

10. Siegel $S$, Noblett $K$, Mangel J, Griebling TL, Sutherland SE, Bird ET, Comiter $C$, Culkin D, Bennett J, Zylstra S, Kan F, Thiery E. Three-year Follow-up Results of a Prospective, Multicenter Study in Overactive Bladder Subjects Treated with Sacral. Neuromodulation Urology 2016;94:57-63.

11. Gajewski JB, Al-Zahrani AA. The long-term efficacy of sacral neuromodulation in the management of intractable cases of bladder pain syndrome: 14 years of experience in one centre. BJU Int 2011;107:12581264.

12. van Voskuilen AC, Oerlemans DJ, Weil EH, de Bie RA, van Kerrebroeck PE. Long term results of neuromodulation by sacral nerve stimulation for lower urinary tract symptoms: a retrospective single center study. Eur Urol 2006;49:366-372.

13. Noblett K, Benson K, Kreder K. Detailed analysis of adverse events and surgical interventions in a large prospective trial of sacral neuromodulation therapy for overactive bladder patients. Neurourol Urodyn 2017;36:11361139.

14. Nambiar AK, Bosch $R$, Cruz $F$, Lemack GE, Thiruchelvam N, Tubaro $A$, Bedretdinova DA, Ambühl D, Farag F, Lombardo R, Schneider MP, Burkhard FC. EAU Guidelines on Assessment and Nonsurgical Management of Urinary Incontinence. Eur Urol 2018;73:596-609.

15. Hanno $P$, Cervigni $M$, Dinis $P$, et al. Bladder pain syndrome. In Abrams $P$, Cardozo L, Wagg A, Wein A eds, Incontinence, 6th edn. Tokyo: International Consultation on Incontinence; 2017: p. 2203-2302.
16. Harvie HS, Amundsen CL, Neuwahl SJ, Honeycutt AA, Lukacz ES, Sung VW, Rogers RG, Ellington D, Ferrando CA, Chermansky CJ, Mazloomdoost D. Thomas S. Cost-Effectiveness of Sacral Neuromodulation versus OnabotulinumtoxinA for Refractory Urgency Urinary Incontinence: Results of the ROSETTA Randomized Trial. J Urol 2020;203:969-977.

17. Chughtai B, Clemens JQ, Thomas D, Sun T, Ghomrawi H, Sedrakyan A. Real World Performance of Sacral Neuromodulation and OnabotulinumtoxinA for Overactive Bladder: Focus on Safety and Cost. J Urol 2020;203:179-184.

18. Weil EH, Ruiz-Cerdá JL, Eerdmans PH, Janknegt RA, Van Kerrebroeck PE. Clinical results of sacral neuromodulation for chronic voiding dysfunction using unilateral sacral foramen electrodes. World J Urol 1998;16:313-321.

19. White WM, Mobley JD, Doggweiler R, Dobmeyer-Dittrich C, Klein FA Incidence and predictors of complications with sacral neuromodulation. Urology 2009;73:731-735.

20. Marcelissen TA, Leong RK, Nieman FH, van Lankveld JJ, van Kerrebroeck $\mathrm{PE}$, de Wachter SG. Psychological and psychiatric factors as predictors for success in sacral neuromodulation treatment. BJU Int 2011;108:1834-1838.

21. Peters KM, Killinger KA, Boura JA. Is sensory testing during lead placement crucial for achieving positive outcomes after sacral neuromodulation? Neurourol Urodyn 2011;30:1489-1492.

22. Amundsen $\mathrm{CL}$, Romero $\mathrm{AA}$, Jamison MG, Webster GD. Sacral neuromodulation for intractable urge incontinence: are there factors associated with cure? Urology 2005;66:746-750.

23. Sherman ND, Jamison MG, Webster GD, Amundsen CL. Sacral neuromodulation for the treatment of refractory urinary urge incontinence after stress incontinence surgery. Am J Obstet Gynecol 2005;193:20832087.

24. Cohen BL, Tunuguntla HS, Gousse A. Predictors of success for first stage neuromodulation: motor versus sensory response. J Urol 2006;175:21782181. 